\title{
AMÉRICA, EL OTRO DE MONTAIGNE Y CERVANTES ${ }^{1}$
}

\author{
AMERICA, MONTAIGNE'S AND CERVANTES'OTHER
}

\author{
José-Miguel MARINAS \\ Universidad Complutense de Madrid \\ marinasjm@gmail.com
}

Resumen: El presente texto reflexiona sobre la mirada que ve las Indias, que ve América. No tanto los detalles de su contenido nuevo, sino la construcción de una nueva manera de apreciar y reparar en el mundo que se produce por el radical acontecimiento del descubrimiento, conquista, colonización y explotación de las Indias Occidentales. Mirar la mirada, por tanto, es la tarea, y no tanto lo visto. Este ejercicio se centra en dos ejemplos cercanos y a la vez descomunales que son Michel de Montaigne y Miguel de Cervantes. Para ello, se darán tres pasos: (a) ligar la mirada americana y la modernidad del sur, (b) presentar algunos indicios y estructura del discurso americano en Montaigne (c) comparar con los indicios y estructura del discurso americano de Cervantes.

Palabras clave: Mirada, América, identidad, Cervantes, Montaigne.

Abstract: The present text reflects on the way the West Indies and America are seen. Not so much the details that come with the new content, but rather the new way of perceiving and considering a world born of the radical event of discovery, conquest, colonization, and exploitation. Therefore examining the perspective, rather than what is seen, is the task at hand. This exercise will focus on two examples that are both similar and at the same time independently important: those of Michel de Montaigne and Miguel de Cervantes. The work will consist of three steps: (a) linking the American perspective with the modern south; (b) presenting some evidence and structure of American rhetoric in Montaigne; (c) and comparing those with examples from Cervantes.

Keywords: Perspective, América, indentity, Cervantes, Montaigne.

\footnotetext{
${ }^{1}$ Una primera versión de este texto fue presentada en el Seminario sobre Escrituras Virreinales, Facultad de Filología, UCM, 2015. Agradezco a Esperanza López Parada y a sus «virreinas» la ocasión de debatir.
} 
$\mathbf{0}$

\section{. Introducción}

Yo comparto la afición americana y en algún momento he querido compartir también el adjetivo que Lezama Lima le dedica a Ortega en ocasión de su ocaso. Lezama se despide de don José llamándole Ortega El americano. Desde el punto de vista del cubano, Ortega quiso entreverar y dar sentido a su discurso filosófico ayudando a la reflexión americana. En mi caso, dejémoslo en algo más modesto y menos puntiagudo: dejémoslo en la convicción de que se puede hablar de una escritura hispanoamericana, latinoamericana, si me permiten, a condición de incluir a España en ese ámbito. Porque América es nuestro otro, nuestro espejo, pero al mismo tiempo -como ocurre con la construcción de las identidades- es otro que está dentro de nosotros. De espejo que aparentemente desde afuera refleja lo nuestro e incluso lo distorsiona, pasa a ser otro sin el cual no sabemos nombrarnos. Y esto, lejos de ser discurso galeato, es la clave de nuestra estructura, Lacan dixit en su estadio del espejo: no hay identidad sin el otro de lo que somos, que incorporamos y a la vez nos tiene a distancia.

\section{La voz primera, quiero decir la primera mirada}

Me sucedió visitando México una de las primeras veces. Caí por un pueblo cerca de Oaxaca o Nueva Antequera. Y allí miré despacio, en vilo, una iglesia, pintada con frescos indígenas, conmovedoras e infinitas cabezas de angelitos.

Y me di cuenta de lo que, para mí, se inauguraba:

un camino real recorrido una y mil veces por los pies morenos y duros de muchachas, mujeres, hombres, niños, indígenas vestidos de los años sesenta, ellas como pimpollos recatados, llenas de ojos que miran como se debió de mirar en el tiempo en que se inauguró la mirada humana ${ }^{2}$

No sé cuándo se inauguró esta mirada. Ni sé si tuvo la rotundidad que por ejemplo Elia Kazan (discutido y todo, pero esa es otra historia) le pone en la boca del joven griego que quiere hacerse a la mar: L'AméricaAméricaAmérica. Nítida voz mediterránea y lamento sin consuelo porque se sabe que allá está lo otro que deseo más que nada en el mundo pero no se me da. Eso y abrir el pensamiento a la captación de lo humano extraño: eso es Montaigne. Eso y no cesar en sostener el deseo: eso es Cervantes.

Qué se hacen de esas miradas de extrañeza con las cosas que vienen de las Indias, con los nuevos sujetos (porque son súbditos, en el francés de Montaigne sujet es antes que nada súbdito) que no se sabe si tienen alma o no. Ni a dónde fueron antes de que los españoles llegaran. A dónde sus almas. Pero aquí ya comenzó la tremenda e irreversible traducción que abrocha el exterminio y la colonización. Hacerlos cristianos, súbditos, productivos (como los lingotes del Celoso extremeño).

\footnotetext{
${ }^{2}$ JM Marinas, Mano de santo (inédito).
} 
Si elijo, de entre otros espejos posibles, de tantos contempladores del horror o de la diferencia, o del mestizaje, a Michel de Montaigne y a Miguel de Cervantes, supongo que es porque a fuer de dos escrituras monumentales e imprescindibles, suponen dos maneras de mirar lo ajeno que se acerca y que nunca acaba de casar con lo que venimos siendo. Nunca casa del todo y sin embargo produce una revolución en la cabeza. Sujeto, mundo, mujer, varón, comunidad, futuro se dirán ya de otra manera. Poco a poco, de forma ni siquiera hoy conclusa...

El otro motivo, además de ver cómo se arma la mirada de lo otro americano para estos dos escritores, es indagar cómo se forma la mirada americana, desde América. Además de cómo les vemos, cómo nos ven. En la intuición de que hay una matriz común que produce efectos e itinerarios divergentes. No sólo la voz americana de Colón, las afirmaciones (en el sentido de afirmarse con fijeza) de los primeros discursos de la colonia. Y me interesa mucho -aunque no es objeto de estas páginasla teorización de la diferencia desde la propia América. Diríamos que los europeos -es una primera hipótesis- quieren comparar, traducir, llegar a una universalización posible (en el mejor de los casos que incluye la diversidad y el conflicto). Mientras que desde América surgirá una voz que trata de mostrar el propio fundamento y creación. La expresión americana, majestuoso tratado de José Lezama Lima, va más allá -como sabemos muy bien- de una lexicografía comparada.

Los berrinches del primer Borges con Albornoz, sobre el habla criolla o porteña, son indicio de una voluntad de nombrar la diferencia desde allí.

La perspectiva teórica de esta reflexión es la que llamamos de la modernidad del sur. Este modelo, que $\mathrm{C}$. Thiebaut ${ }^{3}$ principalmente ha desarrollado y yo he utilizado en algunas investigaciones, tiene una pretensión: considerar que la modernidad no es única ni exclusivamente centroeuropea, racionalista, universalista e ilustrada (siguiendo los parámetros convencionales) sino que cabe hablar de una modernidad del sur. Se trata de un proceso de construcción de la identidad periférica (respecto a Centroeuropa), más narrativa que codicial, más centrada en el sujeto y sus nuevos ethos vitales que en una moral uniforme y descontextualizada. Lo que supone que sujeto, norma y mundo son mudables y son efecto del deseo, la deliberación y el acuerdo. Por eso se puede entender que Montaigne y Cervantes son aquí centrales: ellos fundan esa llamada modernidad del sur.

Presento primero, pues, algunos indicios textuales que rompen y obligan a teorizar de nuevo lo nuevo. Sintetizo después el efecto de heterotopía (radical diferencia analogable) o de utopía (diferencia por proyección de anhelos de aquí sobre aquellas tierras) que ejercen en la perspectiva teórica de ambos.

\section{Montaigne}

Michel de Montaigne es un ensayista y viajero que se caracteriza por una apertura poco común. Curioso y estudioso de lo otro, de lo mudable, de lo que viene, en todos los terrenos. Y, al tiempo, sólidamente anclado en los clásicos como un paisaje al que siempre vuelve, para sacar lecciones

\footnotetext{
${ }^{3}$ Carlos Thiebaut, «Sujeto complejo, identidad narrativa, modernidad del sur» en C. Castilla del Pino: Teoría del personaje, Alianza Editorial, 1999, pp.121-126.
} 
nuevas. Montaigne da testimonio, desde esa modernidad del sur, de la radical novedad del descubrimiento americano. Lo conoce, lo reflexiona y saca de él consecuencias para proponer una nueva política, la que corresponde a una humanidad redefinida.

Procedo primero, brevemente, con los indicios, los lugares textuales de su eco de las Indias. Posteriormente, recojo algunos rasgos de su doctrina política que son efecto de la transformación americana.

\subsection{Indicios}

La apertura al mundo de este pensador y jurista bordelés es notoria y una de sus mayores galas. No sólo habla latín y griego en su infancia antes de dominar el francés, sino que se impregna de toda suerte de referencias librescas y de viaje (como atestigua su Diario del Viaje a Italia ${ }^{4}$ y en sí mismo reúne linajes que desbordan las fronteras francesas, especialmente su ascendencia judía española. Con una madre oriunda de Aragón y de apellido López y un padre que hablaba español y leía libros españoles especialmente a Marco Aurelio ${ }^{5}$.

Los lugares textuales no son excesivos, pero sí abundantes y de fuste, iba a decir tratándose de un escritor francés, aunque mestizo en más de un sentido. Otilia López Fanego -montañista española de primera hora ${ }^{6}$, destaca esta aproximación textual diciendo:

Como es bien sabido, Montaigne no sólo ha dedicado un capítulo completo a hecho tan importante (L. $1^{\circ}$, cap. XXXI) sino que abundan en los Ensayos frecuentes alusiones, incluso extensos fragmentos referentes al acontecimiento que trastocó tan profundamente la imagen del mundo conocido hasta entonces. Aprovechará siempre para insistir en lo que tanto le preocupa: advertir errores, afirmar la necesidad de juzgar con criterio propio por la vía racional, no dejarse llevar por opiniones ajenas por muy consagradas que estén, lo que nos permitirá disfrutar con sus observaciones tan oportunamente expresadas, tan pertinentes y libres de todo conformismo y rutina.

Este es el retrato perfecto de la nueva mirada. La propiedad de una posición que se preocupa por señalar la diferencia (heterotopía) del nuevo mundo, dice Fanego, frente a los teólogos que afirmaban rotundamente que no era nuevo mundo sino continuación de Europa. La variedad de fuentes (sobre todo Mexía, Silva de varia lección; López de Gómara, Historia General de la Indias, cuyas huellas están en el capítulo dedicado a Ramón Sibiuda, libro II, cap. XII; Cap. I, XXIII, 109.

Hay, pues, dos lugares principales: la reflexión sobre los caníbales (libro I, cap. XXX) y la digresión tan afinada del libro III, cap. VI sobre los carruajes.

\footnotetext{
${ }^{4}$ JM Marinas y C. Thiebaut, Diario del Viaje a Italia de Michel de Montaigne, edición trilingüe, Debate-CSIC, 1994.

${ }^{5}$ C. Thiebaut, «'La desolación de esta conquista': Las reflexiones de Montaigne sobre las Indias» en Mercé Boixareu y Robin Lefere (coords.), La Historia de España en la Literatura Francesa. Una fascinación..., Editorial Castalia, Madrid, 2002, pp. 137-147. Es interesante el rastreo de los protoensayistas que el padre seguía de cerca. Así como la discusión de los argumentos de Michel. Agradezco enormemente a Thiebaut esta «guía de lectura».

${ }^{6}$ Sigo particularmente su trabajo «Montaigne y el descubrimiento de América», Cuadernos Hispanoamericanos, 1992, pp. 33-44. Doña Otilia, fallecida en 2004, constante investigadora montañista, nos acompañó a Carlos Thiebaut y a mí mismo en la presentación de nuestro Diario del Viaje a Italia de M. Montaigne, y lo acogió con mucha generosidad.
} 
El primero $\left(\mathrm{I}_{\mathrm{XXII}}{ }^{7}\right)$ presenta de entrada, de pronto, a su narrador de primera mano acerca de las Indias.

He tenido a mi lado, durante mucho tiempo, a un hombre que permaneció diez o doce años en ese otro mundo que ha sido descubierto en nuestro siglo, en el lugar donde Villegagnon desembarcó, llamado por la Francia Antártica («también llamada América», dice Thevet, contemporáneo). Este descubrimiento de un país infinito, parece ser muy importante. No sé si puedo estar seguro de que no se descubra otro en el futuro, habida cuenta de que tantos personajes más grandes que nosotros han errado en esta materia. Temo que nuestros ojos sean más grandes que nuestra tripa y que seamos más curiosos que capaces... ${ }^{8}$

Se trata de una fuente peculiar, resultado de una expedición de protestantes que llega al país de los tupinambas, bahía de Guanabara, actual Río de Janeiro. Este primer indicio tan directo nos trae dos perlas: la mirada etnocéntrica del conquistador y la distancia que Montaigne pretende tomar de ella. El informante y el mundo son vistos así en posteriores fragmentos:

El hombre que tenía conmigo era simple y burdo, lo cual es una condición apropiada para dar testimonio verídico. La gente refinada, en efecto, observa con mayor curiosidad y más cosas, pero las comenta...y (acaba por ) alterar un poco la historia/.../ Se requiere un hombre fiel o uno tan simple /.../El mío era así; y además me ha presentado en distintas ocasiones a muchos marineros y mercaderes que había conocido en su viaje. En consecuencia, me doy por satisfecho con esta información, sin indagar qué dicen los cosmógrafos. Necesitaríamos topógrafos que nos hicieran el relato peculiar de los sitios dónde han estado...

Es la mirada que se atiene a los relatos, que los sopesa y los explora con detalle. Y luego trata de pensarlos en sí mismo desde la variedad de la condición humana. Por ello, el núcleo de este capítulo, en el que no me detendré, es decir, el comentario sobre el canibalismo, es preciso y cuidadoso: «No me enoja que señalemos el bárbaro horror que hay en tal acción, pero sí que juzguemos bien acerca de sus faltas y estemos tan ciegos para las nuestras. Creo que hay más barbarie en comerse a un hombre vivo que en comerlo muerto».

Además de las metáforas y de las criptocitas que los comentaristas ven en este pasaje (que van desde la mención de la matanza de los hugonotes al realismo de la comida eucarística, pasando por ciertos tormentos inflingidos por los portugueses) hay una llamada no al cinismo cultural -en todas partes se cuecen habas- sino a la reflexión moral que no debe dividir entre animados y sin alma.

El otro texto lleno de indicios es el capítulo VI del libro III, en el que diserta sobre los carruajes. Y aquí selecciono, por razón de espacio, esta brillante reflexión:

Nuestro mundo acaba de encontrar otro - ¿y quién nos garantiza que será el último de sus hermanos, habida cuenta de que es éste los demonios, la sibilas y nosotros lo hemos ignorado hasta ahora? -no menos grande, rico y vigoroso que él, y sin embargo tan nuevo y tan niño que todavía le están enseñando el abecé /.../ Era un mundo niño; aun así no lo hemos golpeado ni sometido a nuestra disciplina por la superioridad de nuestro valor de nuestras fuerza naturales, ni lo hemos seducido con nuestra justicia y nuestra bondad, ni

\footnotetext{
${ }^{7}$ Cito por la edición de 1595 llamada de Marie de Gournay, Prólogo de Antoine Compagnon y traducción de J. Bayod Brau. Marie de Gournay, su fille d'alliance, retoma y edita las anotaciones de Montaigne, hechas hasta su fallecimiento de 1592, que eran una tercera versión, tras la de 1580 (libros I y II) y la de 1588 (libros I, II corregidos y aumentados más un libro III).

${ }^{8}$ Libro I, capítulo XXX, pp. 274-275.

${ }^{9}$ Libro I, cap. XXX, pp. 277-278.
} 
subyugado con nuestra grandeza de ánimo. La mayoría de sus respuestas y de las negociaciones hechas con ellos demuestran que no nos eran inferiores en claridad de espíritu natural ni en pertinencia.

El relato minucioso de aspectos de la vida del reino del Perú y del poderío de México compone este friso detallado y poderoso. Por ello resulta admirable el repaso de los fundamentos de la conquista: la disposición del Papa para que España y Portugal se apoderen de estas tierras. Los nativos dicen astucia: menesteroso es el país que pide (que se conviertan, que les den sus recursos), chocante la autoridad de ese Papa que da lo que no es suyo ${ }^{10} \ldots$

Cuando miro el ardor indomable con el que tantos millares de hombres, mujeres y niños se ofrecen y se arrojan tantas veces a peligros inevitables para defender a sus dioses y su libertad, la noble obstinación con la que prefieren soportar sus excesos y dificultades, y la muerte, a someterse al dominio de quienes les han engañado de manera tan infame, y cómo algunos, cuando son capturados, prefieren dejarse desfallecer por el hambre y el ayuno a aceptar vivir gracias al poder de sus enemigos, tan vilmente victorioso, preveo que si les hubieran atacado en igualdad de armas, experiencia y número, el peligro habría sido tanto o más, que el de cualquier otra guerra de las que vemos.

\subsection{Una política nueva}

«Nuestro mundo acaba de encontrar otro». De la misma manera que Montaigne que visita a los naturales de Brasil exhibidos en la corte de Rouen ${ }^{11}$ ( en 1550 y 1562) para ver qué dicen de sí mismos y así entrar en contacto con sus nuevas formas de vida, mediante un dudoso traductor. Allí ve cómo le confiesan su perplejidad ante las formas de autoridad (que un adolescente rey mande sobre súbditos barbados) y también ante el carácter burocrático del mando (entre ellos quien manda entra el primero en combate).

La experiencia americana es una ocasión novedosa para que podamos pensar desde Europa que el mundo es distinto. Es ancho y ajeno. Pero sus consecuencias son precisas y propias.

Montaigne es un pensador moderno y aun trasmoderno ${ }^{12}$, porque potencia la cultura clásica renacentista, pero se abre a un espacio de problemas y de modos de tratarlos que inauguran el barroco. Ser él mismo materia de su libro, como encabeza los ensayos, lo convierte en un pensador radical, equiparable al Descartes que fía en la experiencia crítica del sujeto la fundamentación del mundo y del conocimiento. Montaigne desmonta las evidencias, persigue los indicios de lo nuevo que viene. Por eso le interesa lo americano.

\footnotetext{
${ }^{10}$ Las Casas y López de Gómara son las fuentes principales y comentadas al detalle por Montaigne.

${ }^{11}$ «El primer acto empieza a finales del siglo XV con las grandes exploraciones europeas. Destacan los 37 aztecas exhibidos por Hernán Cortés en la corte real española. Varios cuadros representan una fiesta brasileña organizada en 1550 en la ciudad francesa de Rouen en presencia del rey Enrique II. Contrastan los salvajes pintados de rojo y desnudos con los civilizados bien arropados. En 1562 se volvió a armar otro espectáculo con 50 indígenas de Brasil en la misma ciudad. El filósofo Michel de Montaigne fue uno de los pocos europeos en manifestarles respeto. Les dedicó un ensayo titulado De los caníbales en el que enfatizó: «No hay nada bárbaro ni salvaje en esa nación (...) Cada quien llama barbarie lo que está ajeno a sus costumbres», en Anne Marie Mergier, «El racismo como espectáculo», Proceso.com.mx, 11 diciembre 2011 (internet),

${ }_{12}$ Blas Matamoro, «Montaigne, moderno y trasmoderno», Cuadernos Hispanoamericanos, 1992(509), pp. 15-32
} 
Diríamos que es trasmoderno porque es barroco, en el sentido de un constructor de sentido más allá de los códigos. Por eso dice Blas Matamoro que es antirrenacentista, es decir antirretórico. Excede, podemos concluir, los cánones y los esquemas previos para señalar lo nuevo ${ }^{13}$

«Hablo inquiriendo e ignorando. No enseño, narro» (III,2) y por eso reflexiona sobre lo no sabido, es decir, sobre la condición frágil y finita del ser humano. Este maestro de vida ${ }^{14}$ es un pensador sobre nuestra condición mortal. Pero las vías del camino humano son radicalmente diversas. Él, que viajando a Italia, antes de ser elegido alcalde -cuando Cervantes pena por un oficio en las Indias que compense sus tribulaciones- nos dice que cualquier ruta que elige le viene bien, subraya la radical diversidad del mundo: «el mundo es sólo variedad y desemejanza» (II,2).

¿Y qué temas políticos nos depara? Las paradojas de la amistad -su largo testimonio de la amistad con el joven Étienne de la Boetie-, que atraviesa los Ensayos y resulta emocionante en las añoranzas del Diario de Viaje a Italia. La amistad como filia, como vínculo que hace el vínculo cívico, que no se queda en la privacidad. La desigualdad radical de la servidumbre voluntaria -tema de su joven amigo- es decir nada menos que el fundamento de la obediencia civil que constituye la base de lo político. ¿Por qué poner en manos de alguien las armas de nuestro destino? Tal vez la conversación con el salvaje y su pregunta indiscreta sobre la poca edad del gobernante frente a sus maduros súbditos, le sirvió a Montaigne de analogía con su reflexión más general: en qué radica la obediencia civil.

Pero también, como hemos visto, una perspicaz mirada sobre el fundamento de lo político, es decir, la atribución escolástica de una base en la naturaleza humana. Como si este fuera un código de códigos que determinan las acciones y no -en el espíritu moderno del sur de Montaigne- un desplegarse por las sucesivas experiencias no previstas, no dadas, de la vida. La extensión y la diversidad parecen categorías principales aquí.

La diversidad americana le lleva a Montaigne a preguntarse por la verdadera idiosincrasia de la condición humana. Sigue diciendo expresivamente Blas Matamoro:

El mundo histórico de Montaigne se diseña como descentrado. Es plural y de límites indeterminados. $\mathrm{Su}$ única ratio es su propia diferencia. Una diversidad abstracta que se va llenando de costumbres concretas /.../El mundo es cambiante como el río que roe los cimientos de las casas alzadas en sus riberas (las casas son una metonimia de la costumbre, de lo habitable, del hábito, lo habitual). El otro entonces, es otra cultura, no barbarie, ni salvajismo. El llamado salvaje está más cerca que nosotros de la ingenuidad original y representa, mal que bien, la fábula de la edad dorada /.../ En De los caníbales I,XXI «No cometo el común error de juzgar al otro según lo que soy. Creo con facilidad cosas diversas de mí» ${ }^{15}$

\footnotetext{
${ }^{13}$ Lo cual no excluye trabajos excelentes como el de nuestro maestro Daniel Martin que ha desvelado procedimientos mnemotécnicos - pero para componer el texto, no para anclarlo en nada pasado- bajo los Ensayos de Montaigne y también en El Quijote de Cervantes. L'Architecture des Essais: mémoire artificielle et mithologie, París, Nizet, 1992.

${ }^{14} \mathrm{JM}$ Marinas, Maestro de vida. Selección de Montaigne, Debate, 2000. Prólogo JM Marinas.

${ }^{15}$ B. Matamoro, o.c., pp.18-19.
} 
Este país infinito (la Francia Antártica o América) es más que un territorio cuyo fin no se ve. Es la presencia, no utópica, sino por fin distópica ${ }^{16}$ para quien escribe -pues le obliga a pensar sin calcar la diferencia del distinto y sin tomarlo como su utopía-. Es la variedad y falta de semejanza la que funda la diversidad de lo humano. Tal es su maravillo e intenso testimonio en el Diario del Viaje a Italia. Un friso vivo de las diferencias que no son entomológicas ni curiosas, sino fruto de una profunda violencia que estalla en las guerras de religión europeas.

\section{Cervantes}

Cervantes no pudo pasar a América pero en ella vive en casa propia (Rafael Heliodoro Valle)

Comienzo con esta noticia, que consta en la introducción de la Edición del IV Centenario del Quijote (RAE, 2004).

Conviene recordar que, fresca todavía la tinta de la impresión del Quijote, en la primera mitad de 1605 salieron para América cientos de ejemplares de la novela. Irving Leonard cuenta cómo doscientos sesenta y dos fueron a bordo del Espíritu Santo a México, y que un librero de Alcalá, Juan de Sarriá, remitió a un socio de Lima sesenta bultos de mercancía que viajaron en el Nuestra Señora del Rosario a Cartagena de Indias y de allí a Portobelo, Panamá y El Callao hasta llegar a su destino. Se perdieron en el trayecto varios bultos, pero así comenzó el Quijote su aventura americana. Lo que no había conseguido Cervantes, lo lograba su criatura asentándose en el Nuevo Mundo.

Cervantes, como la España barroca de su tiempo, recibe y digiere poco a poco la condición particular de las Indias. Él es otro que desde su radical diferencia-desde el desconocimiento colombino de su posición, de su ser, Indias occidentales se llaman para no desfacer el entuerto- viene a ser un referente principal de la nueva identidad española. España con Indias es el espacio y el campo semántico que va entrando en la cabeza de los súbditos de los reyes Carlos V, Felipe II y Felipe III. Pero este tentador mundo nuevo, que pronto se convierte en metonimia de la riqueza material (las entrañas de la tierra hechas plata y oro blanco) se hace a la vez metáfora de otra nueva manera de ser. La heterotopía -la diferencia- se convierte en utopía. Toda la saga de marinos, descubridores, apalancados buscavidas y dizque dignos burócratas acotarán un mundo en el que entrar significa estar como súbdito digno del Rey de España y al mismo tiempo como califa en lugar del califa (que era la secreta esperanza, como recordarán, del visir Iznogud), es decir, ejercer una autonomía sin freno aparente. El reino de Jauja, y estar en Jauja y el ser esto jauja son muestras de la gran esperanza americana. La prueba de esa apertura conceptual la da ${ }^{17}$ el primer botón de muestra del Quijote, en que el cura, al hablar de las unidades de una obra teatral -sobre la unidad aristotélica de tiempo, espacio y acción-

\footnotetext{
${ }^{16}$ Roland Barthes habla en numerosos lugares (por ejemplo RB par lui même, Seuil, 1975) de la atopía o no determinación por el lugar para quien escribe. Este despojamiento, por entre la selva de clásicos y de experiencias, creo que le cuadra a Montaigne. Ni utopista ni heterotópico.

${ }^{17}$ Luis Correa-Díaz Cervantes y América / Cervantes en las Américas. Mapa de campo y ensayo de bibliografía razonada, Kassel Barcelona, Edition Reichenmberg, 2006, p.26
} 
¿Qué diré, pues, de la observancia que guardan en los tiempos en que pueden o podían suceder las acciones que representan, sino que he visto comedia que la primera jornada comenzó en Europa, la segunda en Asia, la tercera se acabó en África, y aun, si fuera de cuatro jornadas, la cuarta acabaría en América, y así se hubiera hecho en las cuatro partes del mundo? (RAE, 495)

El mapa se amplía, se acerca el territorio, pero Cervantes, no puede entrar, no llega a pasar a las Indias. Por eso resulta conmovedor ese viaje de los libros tan al hilo de su misma factura.

Cervantes no es Montaigne. Y ahora se verá cómo y por qué. Puedo adelantar que Cervantes vive una vida menos provista y más agitada (que conoce, batallas, derrotas, prisiones moriscas, pleitos $\mathrm{y}$ reclamaciones como funcionario de hacienda, desazones varias). $\mathrm{Y}$ al mismo tiempo vive una presencia, una presión, casi diría, del hecho americano, como escenario menos exótico que los indígenas brasileños en Francia que ve Montaigne.

Su modo de pensar el mundo nuevo y el mundo todo a partir de este hueco de lo diverso, que se llena de ambiciones, plata y prebendas, es menos filosófica en apariencia que la del bordelés. No hay tanta distancia que permita la reflexión política. Cervantes incorpora el hecho americano como esperanza concreta que alivie una vida quebrada, y al mismo tiempo como componente inaugural de una nueva ética, la del sujeto que se autoriza a sí mismo. Lo veremos igualmente (a) en indicios y (b) en su elaboración doctrinal o la ética de Cervantes.

Para lo primero, echo mano de algunos lugares narrativos, principalmente el Quijote y el Celoso extremeño. Para lo segundo, recorro algunos puntos del decir moderno que, siguiendo una sugerencia de Ortega, desarrollé en mi libro Los nombres del Quijote.

\subsection{Indicios}

Presentaré unos pocos ejemplos, lugares cervantinos, en los que la mención de la Indias es explícita y tiene color del habla de la vida cotidiana. No se podrá decir que entre ellos circula un saber docto y específico, sino una serie de caracterizaciones que nos ayudan a captar la distancia con el otro americano que Cervantes vive.

Si acudimos al Quijote, en el capítulo VIII, nos topamos con la primera mención indiana, que por su sencillez apenas llama la atención, pero tiene, a mi juicio, un calado mayor, pues expresa la posición cervantina en general. Se refiere a los frailes benedictinos que cabalgan en dromedarios con naturalidad:

Traían sus antojos de camino y sus quitasoles. Detrás dellos venía un coche, con cuatro o cinco de a caballo que le acompañaban y dos mozos de mulas a pie. Venía en el coche, como después se supo, una señora vizcaína que iba a Sevilla, donde estaba su marido, que pasaba a las Indias con un muy honroso cargo. No venían los frailes con ella, aunque iban el mesmo camino; mas apenas los divisó don Quijote, cuando dijo a su escudero...

Aquí está el vizcaíno al que con brazo en alto y arma presta le vemos servir de quicio entre la primera y la segunda parte del Quijote.

Pasar a las Indias con un muy honroso cargo es expresión que resume lo que Cervantes apeteció más de veinte años antes. Tal como refiere Héctor Brioso (p. 179) Cervantes dirige una carta a don 
Antonio de Eraso, del Consejo de Indias. Esto en 1582 -tras su liberación-, y otra ocho años más tarde (1590) directamente al Rey Felipe II. Cito dos fragmentos breves para dar noticia de lo dramático de la situación:

El secretario Valmaseda ha mostrado conmigo lo que yo, de la que vuestra merced me había de hacer, esperaba, pero ni su solicitud ni mi diligencia pueden contrastar a mi poca dicha. La que he tenido en mi negocio es que el oficio que pedía no se provee por su Majestad: y así es forzoso que aguarde a la carabela de aviso...

Esa carabela de aviso ${ }^{18}$-que dice lo que viene, que traer mercaderías y funcionarios-esa carabela que su sólo nombre nos mete en un hondón de melancolía. El que espera hace lo posible por no decaer en su ánimo («porque entienda que yo no soy yo desagradecido»). Ese patache que viene de las Indias puede traer noticias de los empleos posibles. La segunda referencia es una carta directamente dirigida al Rey. Después de recordarle que su vida ha sido un puro servicio a la corona (ha estado en Lepanto, en Navarino, en Túnez, preso en Argel, Orán y Sevilla en «negocios de la armada») sin que «se le haya hecho merced ninguna». Pide y suplica a SM:

un oficio en las Indias de los tres o cuatro que están vacos, que es uno la contaduría del Nuevo Reino de Granada, o la gobernación de la provincia de Soconusco en Guatemala, o contador de las galeras de Cartagena, o corregidor en la ciudad de la Paz, que con cualquiera de estos oficios Vuestra Majestad le haga merced la recibirá porque es hombre hábil y suficiente y benemérito para que Vuestra Majestad le haga la merced...

Hábil, suficiente y benemérito son tres rasgos que definen al Cervantes como sujeto moderno. Que se ve carente de fortuna. Pero claro en sus haberes personales, como veremos en el segundo apartado de este lugar que ahora recorro. El resultado de la gestión es, de nuevo, deplorable, pues el 6 de junio el relator, Núñez Morquecho, del Consejo de Indias, inserta esta lapidaria anotación: «Busque por acá que se le haga merced». En términos crudos - dice Canavaggio y recoge Brioso Santos- ${ }^{19}$ «vaya con la música a otra parte».

Leído tengo que no fue tan malo este portazo pues le permitió escribir el Quijote y hacerlo en tierra española -lejos de la manigua, diríamos-. Nunca faltan profetas a posteriori...

Las menciones de los detalles de las Indias tienen su interés, porque colocan en contexto la presencia del otro americano. Son breves, por necesidad, y no pretenden más que ilustrar. Aquí están:

Hay una hermosa aventura llamada del barco encantado (capítulo XXIX) en la que, además de divertidísimos juegos de palabras, se trasmite, de modo coloquial, como incorporado al saber y hablar del pueblo, la radical distancia de la experiencia americana.

Para hablar de las Indias nuestros protagonistas se suben a un barco que surca el río Ebro. Ese barco abandonado, ofrecido al modo de los que a tiro les ponían a los caballeros andantes para desplazamiento de socorro de mayor distancia, es tomado por los dos mutantes, que dejando sus bestias

\footnotetext{
18 «Navíos de aviso: fueron de propiedad particular hasta el reinado de Carlos III, momento en que se establecieron los correos marítimos, pasando a ser de propiedad estatal. Las funciones fundamentales de los avisos eran tres: informar sobre la llegada de las flotas y sobre el estado del mercado indiano;

traer numerario de Indias y transportar mercaderías» Temas para la Educación, no 5 , 2009.

${ }^{19}$ Héctor Brioso Santos, colaboración de José Montero Reguera, Cervantes y América, Marcial Pons, 2006.p. 179-181.
} 
atadas en la ribera, y al grito de «santiguarnos y levar ferro», se lanzan al agua. En un momento echan en falta un astrolabio y esto da pie para explicitar algo que nos interesa enormemente: la representación del mundo. La extrañeza del globo terráqueo y su practicabilidad para el viajero, para el navegante, no se resuelve en un mar de dudas sino que se transforma en un sistema de acción. Y esto es lo magistral, a mi modo de ver, del Cervantes que mira los otros lugares. La yuxtaposición de dos sistemas de percepción y medición. El astrolabio y la muerte de los parásitos.

Pero ya habemos de haber salido y caminado por lo menos setecientas o ochocientas leguas; y si yo tuviera aquí un astrolabio con que tomar la altura del polo, yo te dijera las que hemos caminado: aunque o yo se poco o ya hemos pasado o pasaremos presto por la línea equinoccial, que divide y corta los dos contrapuestos polos en igual distancia caminado? / .../

- Y cuando lleguemos a esa leña que vuestra merced dice -preguntó Sancho- ¿cuánto habremos

(luego sigue la mención de Ptolomeo, su cómputo y su ser cosmógrafo, que Sancho cambia en meón o meo, puto y gafo; y concluye la escena así:

- Sabrás, Sancho, que los españoles que se embarcan en Cádiz para ir a la Indias Orientales, una de las señales que tienen para entender que han pasado la línea equinoccial que te he dicho es que a todos lo que van en el navío se les mueren los piojos/.../ y así puedes, Sancho, pasear una mano por un muslo y si topares cosa viva, saldremos de esta duda, y si no, pasado habemos.

- Yo no creo nada deso - respondió Sancho- pero, con todo, haré lo que vuesa merced me manda, aunque no sé para qué hay necesidad de hacer esas experiencias, pues yo veo con mis mismos ojos que no nos habemos apartado de la ribera cinco varas.

l.../

- Haz, Sancho, la averiguación que te he dicho y no te cures de otra, que tú no sabes qué cosa sean coluros, líneas, paralelos, zodiacos, eclípticas, polos, solsticios, equinoccios, planetas, signos, puntos, medida de que se compone la esfera celeste y terrestre.

La empiria autoriza a Sancho, que discretamente se tienta y pesca, a reconocer que aún no han pasado el ecuador, porque ha topado no algo sino «aun algos».

Este episodio navegante, esconde al Cervantes marino de guerra, al cautivo por el Mar Mediterráneo, liberado en la costa luminosa de Denia y casi pasajero a las Indias.

Como prueban los estudiosos, Don Miguel tiene intención de mejorar de vida y solicita «pasar a las Indias» (no he visto expresión más rotunda: es como pasar a otro mundo, pasar a mejor vida). No logra su propósito, no es autorizado. Se queda de marinero en secano

La segunda referencia que espigo es del cap XLII, llamado del Cautivo y el Oidor, donde se hace una clasificación de los rangos en virtud de la proximidad americana. El cautivo es nombrado por su hermano, valiente militar. De tres hermanos el mayor hace la guerra, el mediano estudia leyes en Salamanca, el menor pasa a las Indias:

Ese capitán tan valeroso que decís es mi mayor hermano, el cual, como más fuerte y de más altos pensamientos que yo ni otro hermano mío, escogió el honroso y digno ejercicio de la guerra, que fue uno de los tres caminos que nuestro padre nos propuso, según os dijo vuestro camarada en la conseja que a vuestro parece le oístes. Yo seguí el de las letras, en las cuales Dios y mi diligencia me han puesto en el grado que me veis. Mi menor hermano está en el Pirú, tan rico, que con lo que le ha enviado a mi padre y a mí ha satisfecho la parte que él se llevó, y aun dado a las manos de mi padre con lo que poder hartar su liberalidad natural; y yo ansimesmo he podido con más decencia y autoridad tratarme en mis estudios y llegar al puesto en que me veo. 
Familia, migraciones, cautiverios, rescates, reparaciones... No puede estar fuera de la propia experiencia de Cervantes este relato ejemplar. Y envidiado, podemos suponer.

En la historia de Ricote -capítulo LIIII- cuando se recoge el relato del morisco y tan mediterráneo Ricote, se nombran la Indias como lugar de abundancia. Es lo otro respecto de la escasez peninsular, que ya enseña las orejas, es el motivador real de la carrera americana, que inauguró Colón (por no hablar de Vespucci, ese extraño fraudulento). Y es un pasaje muy rico en matices sobre la identidad europea. Allí está la mención de las Indias:

\begin{abstract}
Doquiera que estamos lloramos por España, que, en fin, nacimos en ella y es nuestra patria natural; en ninguna parte hallamos el acogimiento que nuestra desventura desea, y en Berbería y en todas las partes de áfrica donde esperábamos ser recebidos, acogidos y regalados, allí es donde nos ofenden y maltratan /.../ Es dulce el amor de la patria. Salí como digo de nuestro pueblo y entré en Francia, y aunque allí nos hacían buen acogimiento, quise verlo todo. Pasé a Italia y llegue a Alemania y allí me pareció que se podía vivir con más libertad, porque sus habitantes no miran en muchas delicadezas: cada uno vive como quiere, porque en la mayor parte de ella se vive con libertad de conciencia. Dejé tomada una casa junto a Augusta (Augsburgo); juntéme con estos peregrinos que tiene por costumbre de venir a España muchos de ellos cada año a visitar los santuarios de ella, que los tienen por sus Indias, y por certísima granjería y conocida ganancia. Ándanla casi toda y no hay pueblo ninguno de donde no salgan comidos y bebidos, como suele decirse, y con un real, por lo menos en dineros, y al cabo de su viaje salen con más de cien escudos de sobra, que tocados en oro, o ya en el hueco de los bordones o entre los remiendos de las esclavinas o con la industria que los puede, los sacan del reino y los pasan a sus tierras a pesar de las guardas de los puestos y puertos donde se registran...
\end{abstract}

Resulta llamativo el relato que enmascara en la cultura barroca los cultos populares. El enriquecimiento, la conquista del oro, por más que sea «en dineros», por lo menudo, ese es el estandarte y emblema en que se han convertido las Indias. La ironía de Quevedo: «Nace en las Indias honrado». Aquí las Indias ya están por doquier, ya están dentro. Con tal de que proporcionen el metal rico que de ellas se espera.

El poderío no es sólo material. Ese material en bruto, de la vena mineral (Zacatecas, Taxco) al arca o al canut de los peninsulares. Pero también es lugar de poder espiritual. Esta localización que acabo de mencionar equipara los santuarios y la picaresca en torno a ellos como lugares sagrados, tocados de poderes, de los poderes de los santos -según he mostrado en obra mía reciente.

Casi al final, en el capítulo LXVI, hay un piscolabis precioso entre el cartero, en semblanza de Tosilos, lacayo de duque, quien incita a Sancho de esta manera:

Si vuestra merced quiere un traguito, aunque sea caliente, puro, aquí llevo una calabaza llena de lo caro, con no sé cuántas rajitas de queso de Tronchón, que servirán de llamativo y de despertador de la sed, si acaso está durmiendo.

Quiero el envite -dijo Sancho- y échese el resto de la cortesía y escancie el buen Tosilos, a despecho y a pesar de cuantos encantadores hay en las Indias.

Como veremos, Sancho, o sea Cervantes, remedan y expresan la ruptura brusca de un mundo que se va, con el atributo a fuerzas mágicas, que son su encantamiento hacen ver lo negro blanco, al cartero como cortesano y aquí el temor es que las viandas sean mera apariencia de repente. Por tanto, démosles término rápido. 
Los encantadores de las Indias sin duda tienen que ver con los saberes de la ciencia populartanto en las Indias occidentales como en las más conocidas orientales- con los rituales de magia que los cronistas de Indias anotan cuidadosamente (desde Motolinía y Sahagún hasta el detallado Diego de Landa y sus notas yucatecas)

«No debe nada a nadie - dice Sancho de Don Quijote- que todo lo paga, y más cuando la moneda es locura». Es el quiebro de Sancho, de Cervantes, para poner un punto más alto el oro de las Indias, la quimera del oro.

El celoso extremeño (1613) es -como es de sobra conocido- el otro lugar cervantino en el que las Indias hacen copioso acto de presencia, en la figura de una riqueza que es llave del retorno del indiano (así los llama ya el Covarrubias) y a la vez el extraño factor que se apodera de la vida del tal indiano y de su cohorte de cuasi esclavos.

/.../ Tornó a soplar el viento, impeliendo con tanta fuerza los navíos, que no dejó a nadie en sus asientos; y así, le fue forzoso a Carrizales dejar sus imaginaciones, y dejarse llevar de solos los cuidados que el viaje le ofrecía; el cual viaje fue tan próspero que, sin recebir algún revés ni contraste, llegaron al puerto de Cartagena. Y, por concluir con todo lo que no hace a nuestro propósito, digo que la edad que tenía Filipo cuando pasó a las Indias sería de cuarenta y ocho años; y en veinte que en ellas estuvo, ayudado de su industria y diligencia, alcanzó a tener más de ciento y cincuenta mil pesos ensayados (12 reales y medio cada uno vs los patacones o de a ocho)

Llama la atención la presentación de la persona: más de ciento cincuenta mil pesos ensayados. Llama la atención pues es el nuevo emblema del logro personal. La reducción del sujeto político a esa ética del enriquecimiento que pareciera más protestante que católica, a primera vista. Efectos del viaje al otro mundo...

Viéndose, pues, rico y próspero, tocado del natural deseo que todos tienen de volver a su patria, pospuestos grandes intereses que se le ofrecían, dejando el Pirú, donde había granjeado tanta hacienda, trayéndola toda en barras de oro y plata, y registrada, por quitar inconvenientes, se volvió a España. Desembarcó en Sanlúcar; llegó a Sevilla, tan lleno de años como de riquezas; sacó sus partidas sin zozobras; buscó sus amigos: hallólos todos muertos; quiso partirse a su tierra, aunque ya había tenido nuevas que ningún pariente le había dejado la muerte. Y si cuando iba a Indias, pobre y menesteroso, le iban combatiendo muchos pensamientos, sin dejarle sosegar un punto en mitad de las ondas del mar, no menos ahora en el sosiego de la tierra le combatían, aunque por diferente causa: que si entonces no dormía por pobre, ahora no podía sosegar de rico; que tan pesada carga es la riqueza al que no está usado a tenerla ni sabe usar della, como lo es la pobreza al que continuo la tiene. Cuidados acarrea el oro y cuidados la falta dél; pero los unos se remedian con alcanzar alguna mediana cantidad, y los otros se aumentan mientras más parte se alcanzan.

Y por último, la mención específica de la transformación de la persona. La aparición de un nuevo sujeto que acabará enredado en sus lingotes.

Contemplaba Carrizales en sus barras, no por miserable, porque en algunos años que fue soldado aprendió a ser liberal, sino en lo que había de hacer dellas, a causa que tenerlas en ser era cosa infrutuosa, y tenerlas en casa, cebo para los codiciosos y despertador para los ladrones.

Otro lugar destacado de la idea americana de Cervantes se halla en la obra teatral El rufián dichoso. No se decantan los estudiosos acerca de si es una comedia americana (porque oscila entre 
México y Sevilla) o si es una comedia de $\operatorname{santos}^{20}$. Como dice Villanueva, se trata de la glosa de una noticia cabal de la que A. Cotarelo y Vallador localizan la fuente biográfica de la obra en el libro de Fray Agustín Dávila Padilla: «Historia de la Fundación y discurso de la Provincia de Santiago de Méjico de la Orden de Predicadores», Madrid, 1596: Cervantes nos dice que no reprodujo fielmente los hechos de la vida de Cristóbal de Lugo, después de la Cruz, sino que compone con ella una alegoría de la transición entre dos mundos (América /España; ligereza/ conversión).

\subsection{La ética de Cervantes}

El contexto lo marcan los historiadores que han propuesto una perspectiva más amplia para este período. Quisiera leerla desde la gran aportación de Julio Caro Baroja, cuando de Las formas complejas de la vida religiosa en el XVI y XVII, destaca que hay un ethos nuevo en la vida española, hay nuevos escenarios, que fomentan una ética narrativa, una normativa no de grandes códigos, sino de codicilos: la casuística y la mística tienen su raíz aquí ${ }^{21}$. Creo que esas nuevas tramas vitales, completamente nuevas, engendran nuevas clases (comerciante, burócrata) y dan pie a ese nuevo sujeto del que hablo ahora mismo.

Así, como Brioso recopila y señala:

Cuando Cervantes escribe sus obras, entre 1569 y 1616, cualquier súbdito del Rey de España tiene ante sí un panorama que Américo Castro llama acertadamente «el activismo viajero característico del español del siglo XVI» en su libro de la edad conflictiva (p.198) Un clima que José A. Maravall explica en su libro Estado Moderno y mentalidad social como una verdadera mentalidad expansionista en el XVI español que se congració a los mercaderes y a los ciudadanos en general (pp. 175-176)

Esa nueva cultura, o modo de vivir, que eso es la ética, le da a Cervantes para componer, por entre sus relatos (no es ensayista, qué pena, o no es ensayista: qué bien), un mapa del mundo nuevo. Es lo que Ortega (en sus meditaciones del Quijote) llama el nombrar moderno frente al nombrar románico.

En mi libro de Los nombres del Quijote, intento un poco de sistemática de sus figuras principales. En el nombrar románico -en la organización del mundo y del sujeto moral-, que se quiebra con el descubrimiento de otro mundo y la desestabilización del tenido por eterno e inmutable, radica el punto que Cervantes, con su vida doliente, con su obra preclara, va dejando atrás.

Tenemos aquí la primera señal de la simbólica que me permito llamar 'el nombrar románico', aunque quizá cumpliera llamarlo neoplatónico, o escolástico. Pero si Ortega pone «románico» sus razones más amplias que la mera cuestión onomástica tenía. La iconografía de códices, capiteles, frescos, toda ella girando en torno a una figura humana y terrible, el Pantocrator, sirve de rodrigón de ese nombrar que es románico porque atesora el saber de la academia, de la Escuela, sobre nombres, imágenes y cosas. Una nomenclatura totalizadora, en la que propiamente no hay un reverso salvo lo que no tiene nombre: el mudo mal.

\footnotetext{
${ }^{20}$ Tal es la hipótesis de Juan Manuel Villanueva El rufián dichoso ¿es una típica comedia de santos? Biblioteca Virtual Cervantes, 2001.

${ }^{21}$ J.M. Marinas «Historia: casuística y mística», en VVAA., Judaísmo y Modernidad, Riopiedras,1999.
} 
Vengamos ahora a las caracterizaciones de cada uno de los modos de nombrar. Pues si establecemos las diferencias en un modelo, tenemos más claramente delimitadas las condiciones de posibilidad de cada uno de los modos. Podemos ver a continuación hasta dónde llega y no cada uno de ellos.

Para mayor precisión del modelo me permito mostrar en este cuadro los rasgos que luego iremos comentando:

Tabla 1: Características de los modos de nombrar

\begin{tabular}{|c|c|c|}
\cline { 2 - 3 } \multicolumn{1}{c|}{} & Nombrar románico & Nombrar moderno \\
\hline$(1)$ & Primacía del símbolo & Primacía del icono \\
\hline$(2)$ & Hermenéutica del código & Hermenéutica del mensaje \\
\hline$(3)$ & Mundo armonioso & Mundo desajustado \\
\hline$(4)$ & Nombrar es vertical & Nombrar es horizontal \\
\hline$(5)$ & Nomen est numen & Nomen est omen \\
\hline
\end{tabular}

El nombrar «románico» (cuya fuente documental es Fray Luis) tiene como signos distintivos los siguientes: (1) la primacía de los símbolos sobre los mensajes, (2) el nombrar se basa, pues, exclusivamente en los códigos ya dados, (3) la base es la armonía jerarquizada de un mundo en que coinciden lo uno, bueno y lo verdadero, (4) por ello el nombrar es una operación jerárquica, vertical, precisamente porque (5) los nombres son numinosos, sagrados.

El nombrar moderno (cuya fuente documental es El Quijote) lo podemos acotar en estos rasgos correlativos de los anteriores: (1) la primacía de la construcción icónica frente a los viejos símbolos, (2) el nombrar se basa en los mensajes y en las escenas que estos abren, (3) los planos de la realidad se presentan como descoyuntados o autónomos entre sí y no accesibles al sujeto, (4) nombrar es una operación horizontal: nadie es más que nadie ni en razón ni en rango, (5) los nombres puede ser ominosos, son responsabilidad de quien los porta.

Si nos quedamos en este segundo modo (el primero lo ejemplifiqué en Los nombres de Cristo de Fray Luis, de donde arranca el mero chispazo de la ocurrencia orteguiana), vemos que lo que el Quijote presenta es la configuración y escenificación de un nuevo mundo Ese es el nombrar moderno que, como vimos en la figura comparativa, lo podemos acotar:

\section{(1) El icono, que es una conexión que ahora inventamos, vale más que los viejos símbolos}

Lo que quiero indicar es que el nombrar moderno, el que en el Quijote asoma, tiene más de este carácter abierto del alegorizar (verbo, actividad) que no del apilar y proclamar nombres como símbolos inmutables. Y esa característica de arrimar signos o significantes para producir sentidos es la que la semiótica clásica atribuye a un tipo de actividad significante que gira en torno al icono y no precisamente ante el símbolo o el indicio. El icono -hacer imagen, sea verbal o escrita, grafo o figuraes crear un designador, un representamen decía Peirce, para trazar una relación que no existía. 
Así resulta claro que cuando Don Quijote en sus preparativos se da como tarea lo que alguien llamó hace poco un festival onomástico, lo hace para unir nombres recién hechos con vidas recién inauguradas. Claro que no crea de la nada y, como luego veremos, el calco de figuras ya existentes es reconocible (Quijote arrastra empaque del clásico Lanzarote, y aun del chusco Camilote). Pero sí es radicalmente nueva la aventura del nombrar. Sí que es peculiar -por demodé en la inspiración y, al tiempo, por nunca visto como tal gesto- el afán de nombrar todo lo que se mueve alrededor del señor Alonso Quijano, que ya abandona su decoroso nombre de vecino manchego entre el vértigo del deber a las reglas de la Andante Caballería y la comezón de las aventuras que están por venir.

\section{(2) El nombrar se basa no en lo cerrado, sino en lo nuevo, en los mensajes y en las escenas que estos abren}

En eso, el nombre es como un jeroglífico. Es un mensaje cifrado que cambia, como cambian los escenarios de los personajes, de las y los ciudadanos de los lugares y los tiempos a los que el relato alcanza. Es un objeto poético que nada tiene que ver con el repertorio de referentes que se le atribuyen para razonar su invención: el nombre propio, más allá de los anclajes a que le somete la identificación renacentista: quién es, diga su nombre, comienza a surtir efecto por sí sólo, por su función poética que consiste no en nombrar o en ser nombrado de este modo sino en hacer de modo tal que los interlocutores y el entorno se vean afectados por la misma fuerza del nombre.

Ese es el paso que se recoge ya en los libros de caballería que Cervantes, y el lector no ocioso conocen bien. El punto de partida en la petición de identidad o nombre ante la prueba de la armazón como caballero. El pasaje es del Primaleón, editado en Salamanca en 1512 y en él, el escudero Camilote -que servirá de calco al nombre de nuestro protagonista- solicita al emperador Palmerín la orden de la caballería:

\footnotetext{
- Mi señor, yo soy vuestro natural y vengo a vos pedir por merced que me fagáis caballero porque yo prometí a esta doncella [Maimonda] de no lo ser sino de mano del más alto hombre y mejor que hubiese en el mundo. Y bien sé que en todo él no hay quien con voz se iguale y por esto quiero yo se caballero de nuestras manos, porque de vos me venga el ardimiento.

El emperador, que tan bien le oyó razonar, díjole:

-Amigo, a mi me place de vos facer caballero, mas mucho quería saber quién sois y cómo vos llaman, porque vea si merecéis ser caballero ${ }^{22}$.
}

El punto de llegada, el del poder o irradiación del nombre que surte efecto en las escenas en las que lo reciben aparece muy pronto en la obra quijotesca. Me refiero al colofón de la escena onomástica fundacional. Nombre nuevo recibe el caballo, el mismo caballero y finalmente su dama. Vino a llamarla «Dulcinea del Toboso», porque era natural del Toboso: nombre, a su parecer, músico, y peregrino y significativo, como todos los demás que a él y a sus cosas había puesto [0044]. Que un nombre sea músico por su sonoridad apela a un tiempo del nombrar en el que no se está entrando por la vía de la referencia sino del oído escénico; que sea peregrino implica que es viático para andar y, al

\footnotetext{
${ }^{22}$ Mari Carmen Marín Pina, Motivos y tópicos caballerescos, en Don Quijote de la Mancha, edición de Francisco Rico, volumen complementario, p. 863.
} 
tiempo, que no es común y corriente; que sea significativo implica que no se presta a confusión respecto de otros.

Ese es, pues, el paso al nombrar moderno: reforzar la condición de la persona no sólo por la consistencia de los hechos y las marcas sino, previamente, por el poder prefigurador de la misma «corteza de la letra» del nombre que le imponen.

Función poética, pues, que no se entiende sino trenzada con el clamor que provoca en que quienes lo reciben (por tal nombre le llaman) y por la misma reflexión que quien lo lleva hace de continuo para poder decir «yo sé quién soy».

\section{(3) La realidad no es armoniosa, sino que sus planos se presentan como descoyuntados o autónomos} entre sí y no accesibles al sujeto

La desazón de paisajes en guerra -Montaigne escribe después de las guerras terribles llamadas de religión- contagian al protagonista, y al sujeto civil de una desazón nueva. La de su guerra interior. La de su comezón.

Es la presencia de la duda y el dudar que tiene más de 180 ocurrencias en el libro y que, además de referirse a la sospecha respecto de la condición (noble o plebeya) o la situación personal (ser moza o parecerlo), abre a un espacio de titubeo acerca del entorno que no es banal siquiera mencionar.

Sobre todo, porque no siempre se resuelven las dudas pasando a la acción, al esfuerzo musculoso -en el episodio en que D. Quijote justifica su decisión de abrazar la caballería, se oponen literalmente el verbo dudar («no estoy en dos dedos de ponello en duda») y el verbo sudar como verbo del oficio del caballero) [0138].

El nombrar moderno tiene en cuenta de manera central la posibilidad del engaño, del encantamiento. La chanza cervantina apunta más al fondo de lo que son manifestaciones del delirio de un orate manchego. Los molinos acaban siendo, «sin duda», molinos para Sancho mientras que para su hipertenso señor son ya gigantes verriondos que no cabe sino atizar (sin duda) [0095], así como «sin duda» los encantadores llevan a tal doncella o princesa [0099]. Y en general los modos del mundo llevan consigo la posibilidad de «esa fantasma» (¿por qué en femenino?) que acabamos de ver mencionada y que no podemos, por no incurrir en anacronismo, traer a la colación del psiquismo contemporáneo. Sí parece cierto que el Quijote enseña que junto a la visión está la fantasía. Que junto al darse del mundo a nuestro conocimiento está el darse de nuestra historia inconsciente (con sus «fantasmas») en el momento de mirar.

\section{(4) Nombrar iguala porque nadie tiene la clave dogmática de lo que está abierto: es una operación horizontal en la que nadie es más que nadie ni en razón ni en rango}

El tiempo del Quijote es tiempo de fuertes tensiones e intentos de sofocarlas mediante instituciones y reglamentos de nuevo cuño. La gran variedad de ensayos sobre este asunto convergen en el punto en que la sociedad renacentista que deja atrás el mundo de las jerarquías teológicas asiste a una doble constitución: la de los estados de la ilustración de los siglos XV y XVI que piden 
ciudadanos a los que acabarán sometiendo como súbditos (en el cierre barroco) y, al mismo tiempo, la conciencia emancipatoria de un cierto comunitarismo que formula por vez primera el ideal de una condición humana en lo político y en lo filosófico: la que da como fruto el derecho de gentes, la que anuncia la condición humana de los nuevos súbditos americanos del imperio, la que afirma que cada cual es más hijo de sus obras que de su lugar y estamento de origen. Ello aunque las nuevas jerarquías intenten atar cabos sin ahorrarse nudo, tanto que a algunos, como es el caso del regiamente felicitado como realmente encarcelado y denunciado, Miguel de Cervantes, le empuja contra costumbre a mudar de vida y condición (a volver a salir de casa de mayor: como Montaigne... como Don Quijote mismo).

En esa tensión se mueve este aspecto de los nombres del Quijote. Pues, por un lado, lo igual, el igual es el parejo en condición: y son muchas las referencias a que nadie se salte de estamento, especialmente con motivo de las deliberaciones en torno a la mejora de condición social de Sancho y de su familia. Tanto que chirría en boca de Teresa la voluntad de «igualamiento» que manifiesta la duquesa, entre el agradecimiento y la desmesura:

-Ay -dijo Teresa en oyendo la carta- y qué buena, y qué llana, y qué humilde señora. Con estas tales señoras me entierren a mí no las hidalgas que en este pueblo se usan, que piensan que por ser hidalgas no las ha de tocar el viento, y van a la iglesia con tanta fantasía como si fuesen las mesmas reinas, que no parece sino que tienen a deshonra el mirar a una labradora, y veis aquí donde esta buena señora, con ser duquesa me llama amiga me trata como si fuera su igual, que igual la viera yo con el más alto campanario que hay en la Mancha [1039]

\section{(5) Los nombres no son de suyo santos: puede ser ominosos, y el que lo sean o no es responsabilidad} de quien los ha creado, de quien los lleva y trasmite con él

Si antaño el nombre era sagrado por naturaleza (por teocracia o por teología) ahora puede ser ominoso por la propia actuación de quien lo porta.

En el itinerario quijotesco, por contraposición con el huerto salmantino de Fray Luis, no parece caber una visión edulcorada del mismo. Como en el huerto se nombra el mal pero a diferencia de aquel se trata de recorrer los modos del desastre en los acontecimientos cotidianos, en la catadura de las personas que en el viaje se encuentran caballero y escudero. Los nombres se mudan, empezando por los del propio hidalgo. Pero por debajo de ellos, momento entre dos mudas, hay una apelación a la propia responsabilidad más que a destino externo alguno.

Alguien es bendito cuando sabe bendecir, decir bien su propio nombre con los hechos. Y es maldito cuando no va colmando lo que se espera, más que de su estado y condición, de su carácter. El hábito -que dice Fray Luis en los Nombres- al que la Escuela llamaba estilo y más recientemente llamamos humor, acabará siendo el referente no fatal del hacer y del nombrar. Es lo que podemos ilustrar brevemente recurriendo a un indicio, el de las maldiciones, que en El Quijote atestiguan tanto el paso a lo moderno como la contención ante dicho paso.

Las maldiciones significan lo contrario de recabar el favor del cielo, pero son provocadas por las acciones de quien transgrede. Don Quijote maldice a Sancho en no pocas ocasiones. Igualmente lo hace la sobrina y con idéntica aproximación de nombre propio y petición de ayuda divina: «Malas ínsulas te ahoguen Sancho maldito» [II Cap. 9, [0296]]. «Maldito seas de Dios, mentecato» [0696] y 
«Maldito seas de Dios y de todos sus santos» [0916] y en términos prácticamente idénticos [0977]. Maldiciones reciben los libros de caballerías, el bálsamo, los duelos de Don Quijote, el bachiller -por parte de ama y sobrina- pero especialmente se vinculan a la promesa y responsabilidad que un compromiso implica. [0327].

\section{Referencias bibliográficas}

BARTHES R. (1975) RB par lui même, Seuil.

Brioso Santos, H. (2006) y J. M. Reguera, Cervantes y América, Marcial Pons.

Correa-DíAz, L. (2006): Cervantes y América / Cervantes en las Américas. Mapa de campo y ensayo de bibliografía razonada, Kassel Barcelona, Edition Reichenmberg.

de Cervantes SaAvedra, M. (2004): Don Quijote de la Mancha (Ed. del IV Centenario), Real Academia Española.

López FAnego, O. (1992): «Montaigne y el descubrimiento de América», Cuadernos Hispanoamericanos, pp. 33-44.

MARÍn PINA, M.C. (2015) «Motivos y tópicos caballerescos», en Don Quijote de la Mancha, edición de Francisco Rico, Círculo de Lectores, volumen complementario, p. 863.

MARINAS, J.M. (1999): «Historia: casuística y mística», en VVAA., Judaísmo y Modernidad, Riopiedras.

(2000): Maestro de vida. Selección de Montaigne, Debate.

- (2005): Los nombres del Quijote: una alegoría para la ética moderna, Distriforma, Madrid.

MARINAS, J.M. y C. Thiebaut (1994): Diario del Viaje a Italia de Michel de Montaigne, edición trilingüe, Debate-CSIC.

MAtamoro, B. (1992): «Montaigne, moderno y trasmoderno», Cuadernos Hispanoamericanos, (509), pp. 15-32.

Montaigne, M. (2007): Los ensayos (según la edición de 1595 de Marie de Gournay), prólogo de A. Compagnon y traducción de J. Bayod Brau, Editorial Acantilado.

Thiebaut C. (1999): «Sujeto complejo, identidad narrativa, modernidad del sur» en C. Castilla del Pino: Teoría del personaje, Alianza Editorial, pp.121-126.

(2002): «'La desolación de esta conquista': Las reflexiones de Montaigne sobre las Indias» en M. Boixareu y R. Lefere (coords.), La Historia de España en la Literatura Francesa. Una fascinación..., Editorial Castalia, Madrid, pp. 137-147

VillanueVA, J.M. (2001): El rufián dichoso ¿es una típica comedia de santos?, Biblioteca Virtual Cervantes. 